\title{
Study on the Etiology of the Syndrome of Inappropriate Antidiuretic Hormone (SIADH) Among the Hospital Admitted Patient
}

\author{
Dr. Md. Rakibul Hasan Rashed ${ }^{1 *}$
}

\author{
${ }^{1}$ Junior Consultant, Department of Cardiology, Rajshahi Medical College Hospital, Rajshahi, Bangladesh
}

DOI: $10.36347 /$ sasjm.2022.v08i01.009

| Received: 26.11.2021 | Accepted: 01.01.2022 | Published: 24.01.2022

*Corresponding author: Dr. Md. Rakibul Hasan Rashed MD

Junior Consultant, Department of Cardiology, Rajshahi Medical College Hospital, Rajshahi, Bangladesh

\section{Abstract}

\section{Original Research Article}

Background: The syndrome of inappropriate antidiuretic hormone (SIADH) is a clinical illness that increases antidiuretic hormone (ADH) production or activity due to different disease processes. Normal release of ADH, or arginine vasopressin (AVP), occurs in the posterior lobe of the pituitary gland. SIADH, a hemodynamic disturbance, does not cause secretion of ADH. It is mediated through no osmotic receptors, resulting in water retention and dilutional hyponatremia. Materials methods: This was a cross-sectional observational study carried out by the Department of Medicine, Shaheed Ziaur Rahman Medical College Hospital, Bogura. Total 100 consecutive patients had hyponatremia due to SIADH. All patients were interviewed using standardized questionnaires. Data were analyzed using the statistical packages for social sciences (SPSS) for windows version 16. Results: Most of the patients (42\%) in the study were older people $>60$ years. The average age was 60.69 years. The male-female ratio was 1.43 .1 . The symptoms of hyponatremia were fever (32\%), headache $(34 \%)$, weakness $(40 \%)$. confusion $(48 \%)$, convulsion (19\%) and coma (52\%). Of them, 34\% were hypertensive, and $51 \%$ of patients had a Glasgow coma scale of $3 / 15$. It was observed that the most common etiology of SIADH was hemorrhagic stroke (46\%) then ischemic (41\%). Among the hemorrhagic strokes, $40 \%$ were intracerebral, $4 \%$ were subarachnoid hemorrhage, and $2 \%$ were brain stem hemorrhage. Another etiology was meningitis (4\%). Encephalitis (4\%). Pneumonia (3\%) and pulmonary tuberculosis $(2 \%)$. Serum $\mathrm{Na}^{+}<120 \mathrm{mmol} / \mathrm{L}$ was seen in $38 \%$ patients. Total plasma osmolality was $260.40 \pm 8.51(\mathrm{mmol} / \mathrm{Kg})$, urinary $\mathrm{Na}+$ was $13465 \pm 55.81 \mathrm{mmol} / \mathrm{L}$, urinary osmolality was $408.05 \pm 157.02 \mathrm{mmol} / \mathrm{L}$. S. creatinine was $1.06 \pm 1.02$ $\mathrm{m} / \mathrm{dl}$, and S. uric acid was $3.35 \pm 0.75 \mathrm{mg} / \mathrm{dl}$. Conclusions: The most common symptoms were Coma, confusion, weakness, headache, fever, and convulsion by hemorrhagic stroke and ischemic stroke. Meningitis, encephalitis, pneumonia, and pulmonary TB were the most common causes of SIADH. Serum $\mathrm{Na}^{+}$was low, plasma osmolality, creatinine, uric acid was, and urine osmolality was greater. Hyponatremia should be regularly monitored. Vaptan should be introduced with fluids restriction needed for management of SIADH.

Keywords: SIADH, ADH.

Copyright $(\mathcal{O} 2022$ The Author(s): This is an open-access article distributed under the terms of the Creative Commons Attribution 4.0 International License (CC BY-NC 4.0) which permits unrestricted use, distribution, and reproduction in any medium for non-commercial use provided the original author and source are credited.

\section{INTRODUCTION}

To control the release of antidiuretic hormone $(\mathrm{ADH})$, hypothalamic osmoreceptor cells in the hypothalamus sense changes in the effective osmotic pressure of body fluids. Baroreceptors in the heart and major arteries also release it when the effective circulating volume is reduced. Non-osmotic stimuli, such as nausea, pain, tension, and smoking, can also stimulate vasopressin release in the body $[1,2]$.

For water reabsorption and urine concentration to occur, $\mathrm{ADH}$ in the kidney activates aquaporin 2. This channel is ligand-gated and is stored in endosomes within cells to be inserted into the main apical cells of the collecting duct. When vasopressin-secreting cells or feedback mechanisms are out of week, ADH is released in an abnormally high amount [3].

The balance of water intake regulates the serum sodium concentration, renal filtration, reabsorption of sodium, and $\mathrm{ADH}$-mediated water conservation by the collecting duct. Water balance is mediated by thirst, antidiuretic hormone, the feedback mechanisms of the renin-angiotensin-aldosterone system, and renal handling of filtered sodium and water. Disorders in any one of these components of sodium balance can result in hyponatremia [4]. 
According to various studies, between 2.5 and $16 \%$ of hospitalized patients have hyponatremia. Hyponatremia, defined as a serum sodium content of less than $130 \mathrm{mEq} / \mathrm{L}$, was found in $2.9 \%$ of the subjects in another investigation. Acute hyponatremia was also found to be $0.8 \%$. Women, particularly extremely young or elderly, are more susceptible to variations in blood sodium concentrations. Hyponatremia in men is more likely to be mild or moderate than severe [5].

Those with proven hyponatremia (sodium 130 $\mathrm{mEq} / \mathrm{L}$ ) had a mortality risk 60 -fold higher than patients without established hyponatremia. Being hospitalized, having an immediate onset, and severe hyponatremia are risk factors for increased morbidity and treatment use [6].

Hyponatremia is central nervous system malfunction results in elevated intracranial pressure, and symptoms and signs of hyponatremia are directly linked to the severity and acuity of the hyponatremia. In the beginning, the symptoms include anorexia and nausea, followed by anger and bewilderment and muscular cramps. Seizure, Coma, and obtundation. Moderate to chronic hyponatremia can cause patients to have slower reactions, cognitive slowness, and ataxia, leading to frequent falls [7]. There is a high risk of lifethreatening consequences if sodium concentration falls below 15-105 mEq/L [8].

History will be taken to rule out other conditions (hypovolemic, hypervolemic, and even some systolic) that might be causing hyponatremia. Bronchogenic carcinoma was the first cancer to be linked to the disease. SIADH can be induced by various medicinal drugs, including psychotropics, anticonvulsants, and antidepressants [9]. Additionally, SIADH should be distinguished from hyponatremia that occurs in the hospital due to excessive hypotonic IV fluid administration [10].

The clinical contexts that cause SIADH are CNS disorder (Stroke, Infection. Trauma, Tumours, GBS), Pulmonary disorder (Tuberculosis, Pneumonia, Abscess, Obstructive lung disease), Drugs (Anticonvulsant, Antidepressant, Antipsychotic, Hypoglycaemics, Cytotoxic, Opiates, NSAIDs), Cancers (Lung, colon). Prior to management, the approximate sodium deficit can be estimated by using the following formula (consider $0.5 \mathrm{~L} / \mathrm{kg}$ for females): $\mathrm{Na}+$ Deficit $(\mathrm{mEq})=($ Desired $\mathrm{Na}+-$ Measured $\mathrm{Na}+)$ $\mathrm{X} 0.6 \mathrm{X}$ Weight $(\mathrm{kg})$ and the rate of correction can be $0.5-2 \mathrm{mEq} / \mathrm{L} / \mathrm{h}[11]$.

In order to avoid central pontine myelinolysis (CPM) caused by hyponatremia-induced neurologic symptoms, the total amount of correction should not exceed $15 \mathrm{mEq} / \mathrm{L}$ in 24 hours during treatment [12]. SIADH can be corrected with successful pulmonary or
CNS diseases therapy. Drug-induced SIADH can be remedied quickly and completely by discontinuing the offending medication. Severe hyponatremia or neurologic symptoms may lead to irreversible neurologic impairment in patients.

\section{OBJECTIVES}

General

- To see the etiology of the syndrome of inappropriate antidiuretic hormone.

\section{Specific}

- To see patient demographic profile.

- To see the specific clinical features of SIADH.

\section{REVIEW OF LITERATURE}

Hyponatremia is a common cause of hypotonicity due to the syndrome of inappropriate antidiuretic hormone secretion (SIADH). SIADH may be difficult to differentiate from other hypotonicity causes, such as salt deprivation, however basic and easily available biological measures can aid in the diagnosis. Urea levels tend to be greater in SIADH for older individuals, although this is less specific because of their decreased ability to remove urea. SIADH patients $(70 \%)$ are more likely than salt-depleted individuals to have low uric acid levels (40\%). In individuals with SIADH, the anion gap is often reduced.

While the urea and uric acid levels are low in individuals with hyponatremia. Patients with SIADH have high urine sodium $(\mathrm{Na}+;>30 \mathrm{mEq} / \mathrm{L})$, and most of them will have a high fractional excretion of $\mathrm{Na}^{+}(>0.5$ percent in 70 percent of cases), which reflects salt consumption. V2 antagonists may be useful in individuals with low urine osmolality, whereas water restriction or urea may help those with higher urine osmolality (>600 mOsm/kg) [13].

If a hyponatremia patient shows signs of SIADH, it's important to rule it out. A precise diagnosis necessitates an in-depth physical examination, as well as a thorough review of the patient's medical history, including any coexisting conditions, drugs, and symptoms with appropriate tests must be performed to diagnose exclusion. [14].

A proper diagnosis and treatment of hyponatremia are critical since it is a sign of many underlying disorders and can be a source of morbidity. Sodium and water balance disorder is a common cause of hyponatremia and is diagnosed by an exclusion algorithm in the absence of renal disease or any identifiable non-osmotic stimulus capable of inducing antidiuretic hormone (ADH) release according to its definition. A substantial shift in the condition's terminology, from the syndrome of improper secretion of ADH (SIADH) to today's SIAD, reflects how far our understanding of it has progressed in the previous several years. SIAD is commonly found in hospitalized 
patients, with a prevalence of up to a third of those surveyed reporting symptoms. This comprehensive study discusses the most up-to-date information on the pathophysiology, categorization, management, and treatment of SIAD in detail, including vaptans [15].

In people with cancer, hyponatremia is a frequent fluid and electrolyte imbalance. Hyponatremia can be caused by various factors, although the syndrome of abnormal antidiuretic hormone (SIADH) production is the most prevalent. It is possible to have mild symptoms of SIADH, but they can quickly escalate to life-threatening seizures or Coma, and even death if left untreated. The frequent and continuing interaction that oncology nurses have with their patients puts them in a unique position to identify patients who are at risk for developing SIADH and those who already have symptoms. As the disease progresses, symptoms become more pronounced and might be confused for those of other conditions. The pathogenesis, risk factors, symptoms, diagnosis, therapy, and nursing care of SIADH are discussed [16].

As far as we know, SIADH and nonsteroidal anti-inflammatory medication (NSAID) usage have never been associated with the syndrome of inappropriate antidiuretic hormone (SIADH). We describe a rare incidence of SIADH that was effectively treated with tolvaptan after ibuprofen usage. We saw a 76-year-old guy who was complaining of lumbar and epigastric pain. Ibuprofen 400mg twice a day was his analgesic of choice. Diagnosis of SIADH and rapid cessation of the ibuprofen were made after a laboratory test revealed low levels of salt and chloride. Imaging studies were able to rule out cancers and illnesses of the brain and lungs. As a result, tolvaptan was begun at an initial dose of $7.5 \mathrm{mg}$ per day, increased to a maximum of $15 \mathrm{mg}$ per day after 5 days of treatment. After eight days of therapy, the patient's salt levels began to rise to normal levels. Tolvaptan was gradually titrated up to full suspension in the following weeks, and the salt levels remained normal after that [17].

\section{Diagnosis}

In the absence of a single laboratory test to confirm the diagnosis, SIADH is best defined by the classic Batter-Schwartz criteria, which can be summarized as follows [22].

- Hyponatremia with the corresponding hypoosmolality

- Continued renal excretion of sodium

- Urine less than maximally dilute

- Absence of clinical evidence of volume depletion

- Absence of other causes of hyponatremia

- Correction of hyponatremia by fluid restriction.

The following laboratory tests mast be helpful in the diagnosis of SIADH:

- Serum sodium, potassium chloride, and bicarbonate

- Plasma osmolality
- Serum creatinine

- Blood urea nitrogen

- Blood glucose

- Urine osmolality

- Serum uric acid

- Serum cortisol

- Thyroid-stimulating hormone

- The patient's volume should be assessed clinically to help rule out the presence of hypovolemia.

Imaging studies that may be considered include the following:

X-rays of the chest (for detection of an underlying pulmonary cause of SIADH) Magnetic resonance imaging (MRI) or computed tomography (CT) of the head (for detection of cerebral edema occurring as a complication of SIADH, for identification of a CNS disorder responsible for SIADH, or for helping to rule out other potential causes of a change in neurologic status).

\section{Clinical Features}

The severity of hyponatremia and the rate at which hyponatremia develops affect the signs and symptoms of SIADH. Nonspecific symptoms, such as anorexia, nausea, vomiting, irritability, headaches, and [23], can occur in individuals whose sodium concentration has declined steadily over a lengthy period of time. More symptoms can be found in people who have experienced abrupt drops in salt content. Regardless of the pace of reduction, any blood sodium concentration or serum osmolality lower than 120 $\mathrm{mEq} / \mathrm{L}$ or $240 \mathrm{mOsm} / \mathrm{kg}$ is deemed dangerous. Neurologic complications can occur in people with hyponatremia at this level. These include symptoms including headaches and nausea, muscular cramping, hyporeflexia, disorientation, convulsions, and death if the condition isn't treated [6].

\section{Clinical consequences of hyponatremia due to SIADH}

Hyponatremia notices a wide range of symptoms, which are all connected to how severe the hyponatremia is as well as the rate at which the plasma sodium concentration changes. Patients with moderate hyponatremia (plasma sodium concentration > $130 \mathrm{mmol} / \mathrm{l}$ ) are asymptomatic. There is a risk of anorexia, nausea, vomiting, and abdominal discomfort with plasma sodium values between 125 and 130 millimol/L. Excitation, disorientation, hallucinations, incontinence, and other neurological symptoms are common when plasma sodium concentrations drop to 115-125mmoll. Since hyponatremia causes an increase in intracranial pressure, hyponatremia less than 115 mmol can lead to dangerous neurological consequences such as seizures and Coma. Other factors, such as pyrexia, hypoxia, and hypercapnia, increase the likelihood of hyponatremia-related symptoms even if biochemical severity is the most important factor. The start of symptoms may be delayed if an intracranial 
sickness, a space-occupying lesion, or neurosurgical surgery [8].

The pace at which plasma sodium concentration fluctuates is another important factor in determining when symptoms first appear or how severe they become. Symptoms are more common if the decline in plasma sodium is fast and occur more frequently at higher plasma sodium values than at lower ones. Even in situations of severe hyponatremia, chronic hyponatremia can be a generally asymptomatic illness. When a person suffers from acute hyponatremia, edema develops in the brain, which can lead to increased intracranial pressure, brain herniation, hypoxia, and even death. Due to the availability of brain adaptation mechanisms, many individuals with persistent hyponatremia display no evident ill-effects despite severe biochemical hyponatremia. Intracerebral fluid is lost, salt and potassium are depleted, and water is prevented from accumulating in the brain. [3].

\section{Hyponatremia due to SIADH}

Diagnose SIADH by distinguishing it from other forms of hyponatremia, which is the first step. Hyponatremia may be dilutional, depleted, or redistributed in nature. A pragmatic approach to hyponatremia has been established in ordinary clinical practice, based on clinical and biochemical estimations of extracellular volume status. Hypovolaemic, euvolemic, and hypervolemic causes of hyponatremia can be classified as follows: The benefit of this categorization in our experience is that it is easily comprehended by practitioners who are not experts in hyponatremia. In practice, it can be difficult to tell the difference between moderate hypovolemia and euvolemia, despite the unique clinical symptoms of each category. Hyponatremia has a wide range of symptoms; thus, a precise diagnosis is critical for proper treatment. A lack of serum urea in elderly hypovolemic individuals may make it difficult to identify hyponatremia, as SIADH may induce low urine sodium owing to starvation. An isotonic saline infusion may be useful in several situations. Isotonic saline infusion has been demonstrated to enhance plasma sodium levels in individuals with SIADH whose urine osmolality is $500 \mathrm{mOsm} / \mathrm{kg}$.

\section{Management of SIADH}

- To raise blood sodium levels, long-term fluid restriction of 1,200-1,800 $\mathrm{mL} /$ day will cause a decrease in overall body water intake.

- For those who are very afflicted (severe confusion, convulsions, or coma) intravenous administration of hypotonic saline (3\%) for 3-4 hours is recommended.

- In chronic circumstances, fluid restrictions are difficult to maintain can be treated with Demeclocycline since it is the most effective vasopressin (ADH/AVP) inhibitor available. On the other hand, Demeclocycline takes 2-3 days to take action and has a long list of adverse effects, including photosensitivity of the skin and nephrotoxicity [24]. The long-term effects of urea oral daily consumption in melanosis and brain injury have been positive. However, there are some drawbacks, such as unpleasant taste and the risk of hepatic encephalopathy in patients with hepatitis.

- Conivaptan is a vasopressin receptor antagonist that works against both Vin and V. Acute hyponatremia (such as hypothyroidism or adrenal insufficiency) in hospitalized patients is the primary use of this drug.

- Tolvaptan - an antagonist of the V2 vasopressin receptor. Combined analysis of the 2 trials showed an improvement in hyponatremia in both the short term (primary sodium change in average AUC: $3.62+1-2.68$ and $4.35+/-287$ ) and long term with long term maintenance (primary sodium change in average AUC: $6.22+/-422$ and $6.20+/-4.92$ ), at 4 days and 30 days, respectively. Tolvaptan side effect profile is minimal Discontinuation of the Tolvaptan showed return of hyponatremia to control values at their respective time frames [25].

- Care must be taken when correcting hyponatremia. A rapid rise in the sodium level may cause central pontine myelinolysis. 50 Avoid correction by more than $12 \mathrm{mEq} / \mathrm{L} /$ day. Initial treatment with hypertonic saline may abruptly lead to a rapid dilute diuresis and a fall in $\mathrm{ADH}$. Rapid diuresis may lead to an over-rapid rise in serum sodium and should be managed appropriately.

\section{MATERIALS AND METHODS}

This was a cross-sectional observational study carried out by the Department of Medicine, Shaheed Ziaur Rahman Medical College Hospital, Bogura. From November 2011 to April 2012. All patients were interviewed using standardized questionnaires with the Purposive consecutive sampling method. Total 100 consecutive patients had hyponatremia due to SIADH.

\section{Inclusion Criteria}

- Case of hyponatremia with plasma sodium typically $130 \mathrm{mmol} / \mathrm{L}$

- CSSs in whom clinical context may suspect SIADH +

- $\quad$ Age $>12$ years

\section{Exclusion Criteria}

- Cases in whom criteria for SIADH are not fulfilled

- Cases of hyponatremia in whom other significant causes are present, viz. congestive cardiac failure, nephrotic syndrome, chronic kidney disease, chronic liver disease, Addison's disease, hypothyroidism diuretic therapy, polydipsia, burns, diarrhea, vomiting, and hypotonic IV fluid

- Cases who failed to complete the evaluation and denied participating 


\section{The procedure of data analysis and interpretation}

Statistical package for the social - science (SPSS) version 16.0 for windows was used to analyze the data. Different tables were constructed according to findings. Categorical variables were expressed as a proportion (percentage), and numerical data were expressed as ranges.

\section{Operational definitions}

SIADH: Diagnosis by the following criteria

- Plasma sodium typically $<130 \mathrm{mmol} / \mathrm{L}$

- Plasma osmolality $<270 \mathrm{mmol} / \mathrm{L}$

- Urine osmolality $>150 \mathrm{mmol} / \mathrm{l}$

- Urine sodium $>30 \mathrm{mmol} / \mathrm{l}$

- Low normal plasma urea, creatinine, uric acid

Hyponatremia: Plasma sodium concentration $<130$ $\mathrm{mmol} / \mathrm{L}$. Plasma osmolality $(\mathrm{mmol} / \mathrm{L})=2(\mathrm{Na}+)+$ glucose + Urea.
Pneumonia: Acute respiratory illness associated with recently developed radiological pulmonary shadowing, segmental, lobar, or multilobe. It is proved by serology and culture.

Pulmonary TB: As per national guidelines.

Encephalitis: Both clinically and biochemically proved.

Meningitis: Both clinically and appropriate laboratory support

HTN: As per JNC7 criteria.

\section{RESULTS}

Table I: Age distribution of the patients $(n=100)$

\begin{tabular}{|c|c|c|c|}
\hline Age in years & No. of patients & Percentage (\%) & \multirow{2}{*}{ Mean \pm SD } \\
\hline $21-30$ & 6 & 6.0 & \\
\hline $31-40$ & 1 & 1.0 & \multirow{6}{*}{$60.69 \pm 413.60$} \\
\hline $41-50$ & 20 & 20.0 & \\
\hline $51-60$ & 31 & 31.0 & \\
\hline$>60$ & 42 & 42.0 & \\
\hline Total & 100 & 100.0 & \\
\hline
\end{tabular}

The table shows that the maximum $(42 \%)$ patients were $>60$ years old, followed by $31 \%$ were 51 -
60 years, $20 \%$ were $41-50$ years, $6 \%$ were $21-30$ years, and $1 \%$ was 31.40 years. The average age was 60 years.

Tablo Il: Sex distribution of the patients $(n=100)$

\begin{tabular}{|c|c|c|c|}
\hline Sex & No. of patients & Percentage (\%) & Male-female ratio \\
\hline Male & 59 & 59.0 & \multirow{2}{*}{$1.43: 1$} \\
\hline Female & 41 & 41.0 & \\
\hline Total & 100 & 100.0 & \\
\hline
\end{tabular}

The table shows $59 \%$ were male and $41 \%$ were female. The male-female ratio was 1.43:1.

Table Ill: Clinical presentation of the patients $(n=100)$

\begin{tabular}{|c|c|c|c|}
\hline \multicolumn{2}{|c|}{ Clinical presentation } & No. of patients & Percentage (\%) \\
\hline \multirow{2}{*}{ Fever } & Yes & 32 & 32.0 \\
\cline { 2 - 4 } & No & 68 & 68.0 \\
\hline \multirow{3}{*}{ Headache } & Yes & 34 & 34.0 \\
\cline { 2 - 4 } & No & 66 & 66.0 \\
\hline Confusion & Yes & 40 & 40.0 \\
\cline { 2 - 4 } & No & 60 & 60.0 \\
\cline { 2 - 4 } & Yes & 48 & 48.0 \\
\cline { 2 - 4 } Convulsion & No & 52 & 52.0 \\
\cline { 2 - 4 } & No & 19 & 19.0 \\
\hline \multirow{2}{*}{ Coma } & Yes & 51 & 81.0 \\
\cline { 2 - 4 } & No & 48 & 52.0 \\
\hline
\end{tabular}

The table shows $32 \%$ had a fever, $34 \%$ had a headache, $40 \%$ had a weakness, $48 \%$ had confusion, $19 \%$ had a convulsion and $52 \%$ had Coma. 
Table IV: Past medical history of the patients $(\mathbf{n}=100)$

\begin{tabular}{|c|c|c|}
\hline History & Frequency & Percentage (\%) \\
\hline HTN & 34 & 34.0 \\
\hline None & 66 & 66.0 \\
\hline Total & 100 & 100.0 \\
\hline
\end{tabular}

The table shows $34 \%$ had a history of hypertension and $66 \%$ had no significant past medical history, No. of patients.

Table V: Glasgow coma scale status of the patients (GCS)

\begin{tabular}{|c|c|c|}
\hline GCS & No. of patients & Percentage (\%) \\
\hline $3 / 15$ & 51 & 51.0 \\
\hline $5 / 15$ & 5 & 5.0 \\
\hline $6 / 15$ & 6 & 6.0 \\
\hline $7 / 15$ & 6 & 6.0 \\
\hline $8 / 15$ & 9 & 9.0 \\
\hline $9 / 15$ & 2 & 2.0 \\
\hline $10 / 15$ & 14 & 14.0 \\
\hline $15 / 15$ & 7 & 7.0 \\
\hline Total & 100 & 100.0 \\
\hline
\end{tabular}

Table shows maximum (51\%) GCS were $3 / 15$ followed by $14 \%$ GCS were $10 / 15,9 \%$ GCS were $8 / 15$,
$7 \%$ GCS were $15 / 15,7 / 15,6 / 15,5 \%$ GCS were $5 / 15$ and $2 \%$ GCS were $9 / 15$.

Table VI: Cause of SIADH of the patients $(n=100)$

\begin{tabular}{|c|c|c|}
\hline Cause & No. of patients & Percentage (\%) \\
\hline Haemorrhagic stroke & 46 & 46.0 \\
\hline Intracerebral & 40 & 40.0 \\
\hline Subarachnoid & 4 & 4.0 \\
\hline Pontine (Brain stem) & 2 & 2.0 \\
\hline Ischemic stroke & 41 & 41.0 \\
\hline Pneumonia & 3 & 3.0 \\
\hline Pulmonary tuberculosis & 2 & 2.0 \\
\hline Encephalitis & 4 & 4.0 \\
\hline Meningitis & 4 & 4.0 \\
\hline Total & 100 & 100.0 \\
\hline
\end{tabular}

The table shows the most common cause of SIADH was hemorrhagic stroke $(46 \%)$ then ischemic stroke $(41 \%)$. Other's cause was encephalitis $(4 \%)$, meningitis (4\%), pneumonia (3\%), and pulmonary tuberculosis $(2 \%)$.

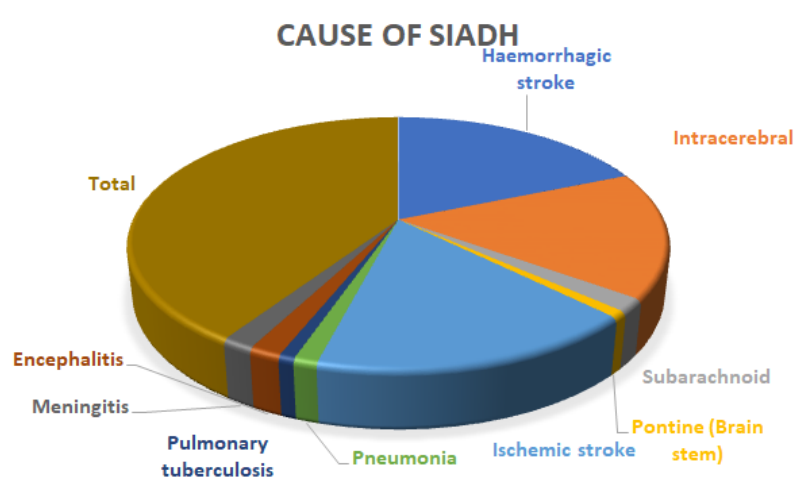

Fig-1: Shows the most common cause of SIADH 
Table Vll: Level of serum $\mathrm{Na}+$ of the patients $(n=100)$

\begin{tabular}{|c|c|c|c|}
\hline Serum Na & No. of patients & Percentage (\%) & \multirow{2}{*}{ Mean \pm SD } \\
\cline { 1 - 3 } $100(\mathrm{mmol} / \mathrm{L})$ & 0 & 00 & \multirow{2}{*}{$1.40 \pm 4.57$} \\
\cline { 1 - 3 } $100-110(\mathrm{mmol} / \mathrm{L})$ & 4 & 38.0 & \\
\cline { 1 - 3 } $111-120(\mathrm{mmol} / \mathrm{L})$ & 38 & 58.0 & \\
\hline$>120(\mathrm{mmol} / \mathrm{L})$ & 58 & 100.0 & \\
\hline Total & 100 & &
\end{tabular}

Table shows maximum (58\%) patient serum sodium were $>120 \mathrm{mmol} / \mathrm{L}$ followed by $38 \%$ serum sodium were $111-120 \mathrm{mmol} / \mathrm{L}$ and $4 \%$ serum sodium were $100-110 \mathrm{mmol} / \mathrm{L}$. The average serum sodium was $121.40 \mathrm{mmol} /$

Table VIll: Biochemical characteristics of the patients $(n=100)$

\begin{tabular}{|c|c|c|}
\hline Characteristics & No. of patients & Mean \pm SD \\
\hline Total plasma osmolality $(\mathrm{mmol} / \mathrm{kg})$ & 100 & $260.40 \pm 18.51$ \\
\hline Urinary Na+ $(\mathrm{mmol} / \mathrm{L})$ & 100 & $134.65 \pm 55.81$ \\
\hline S. creatinine $(\mathrm{mg} / \mathrm{dl})$ & 100 & $408.05 \pm 157.02$ \\
\hline S. Uric acid $(\mathrm{mg} / \mathrm{dl})$ & 100 & $3.35 \pm 0.75$ \\
\hline
\end{tabular}

The table shows Mean \pm SD of total plasma osmolality was $260.40 \pm 8.51(\mathrm{mmol} / \mathrm{Kg})$. Urinary $\mathrm{Na}+$ was $134.65 \pm 55.81 \mathrm{mmol} / \mathrm{L}$, urinary osmolality was
408.05 $\pm 157.02 \mathrm{mmol} / \mathrm{L}, \mathrm{S}$. creatinine was $1.06 \pm 1.02$ $\mathrm{m} / \mathrm{dl}$, and $\mathrm{S}$. uric acid was $3.35 \pm 0.75 \mathrm{mg} / \mathrm{dl}$.

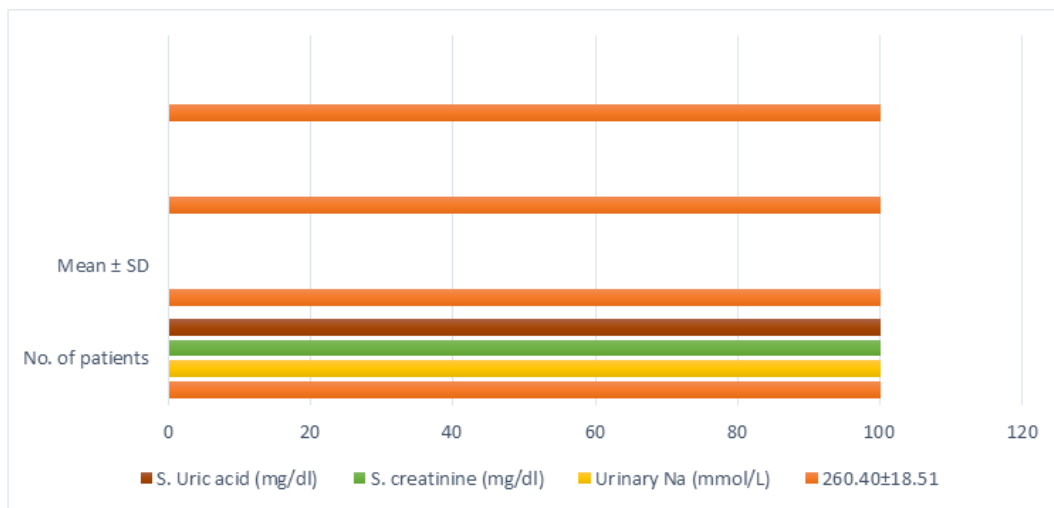

Fig-2: Biochemical characteristics of the patients

\section{DISCUSSION}

In hospitalized patients, the syndrome of inappropriate antidiuretic hormone secretion (SIADH) is the most common cause of euvolemic hyponatremia. Despite being described more than 50 years ago, the management of SIADH is still controversial. [17] The SIADH is associated with hyponatremia without edema [26], caused by stimulating the release of vascpressin or potentiating its action on the renal tubules. The symptoms of SIADH include lethargy. Headache, insomnia, nervousness, apathy, agitation, confusion, convulsions, and Coma are decided by the rate of fall in serum sodium concentration Patients who have hyponatremia and concentrated urine (osmolality >300 $\mathrm{mOsm} / \mathrm{kg}$ ) should be suspected to have SIADH.

The distribution of inappropriate secretion of antidiuretic hormone (SIADH) syndrome in Bangladesh is not well known. Central nervous system and respiratory system diseases, tumors, and drugs are common etiological factors for SIADH. The present study was conducted among the patients who attended the inpatient department of medicine of Shaheed Ziaur Rahman Medical College Hospital from November 2011 to April 2012. The relative details of the syndrome of inappropriate secretion of antidiuretic hormone (SIADH) among 100 cases of the present series were observed.

It was observed that the most common etiology of SIADH was hemorrhagic stroke (46\%) then ischemic stroke (41\%). Another etiologies were meningitis (4\%). Encephalitis (4\%). Pneumonia (3\%) and pulmonary tuberculosis $(2 \%)$. Previously published literature reported SIADH is also commonly associated with intracranial diseases, particularly traumatic brain injury [27] be where almost all cases resolve spontaneously with recovery from brain injury. Over $50 \%$ of the patients with subarachnoid hemorrhage develop hyponatremia in the first week following the bleed, and 70\% were due to SIADH [28]. Pulmonary 50 conditions such as pneumonia, tuberculosis, acute respiratory failure. asthma, and atelectasis, have also 
been associated with increased production of ADH [29]. SIADH is the most common cause of nonmonomeric hyponatremia, which occurs due to non-physiologic $\mathrm{ADH}$ release from the posterior pituitary or an ectopic source such as carcinoma of the bronchi.

Infections such as abscess or tuberculosis of the lungs or brain, viral or bacterial encephalitis or meningitis, pulmonary nocardiosis, ophthalmic herpes zoster, congenital insufficiency of the anterior pituitary gland, asthma, the Guillain-Barre syndrome, multiple sclerosis, and sin nasal neuroendocrine carcinoma are among the more common. Marathon runners and those who use certain antidepressant medications (e.g., SSRIs) are at an increased risk of cerebral vascular occlusive disease (CVO), as do people who take certain antidepressants (e.g., SSRIs) [30].

This study showed the symptom of hyponatremia were fever $(32 \%)$, headache $(34 \%)$, weakness $(40 \%)$, confusion $(48 \%)$, convulsion $(19 \%)$, and Coma (52\%). Ashraf et al., [31] reported hyponatremia symptoms were headache and lethargy. Obtundation, and eventually seizure, Coma, and respiratory arrest if the plasma sodium concentration falls below 115 to $120 \mathrm{mmol} / \mathrm{l}$. Another study reported Lieh-Lai et al., the symptoms of SIADH are varied and range from mild pain, muscle cramps, and anorexia to nausea, vomiting, confusion, Coma, convulsion, and death. Low urinary output and increased specific gravity of the urine are usually the early signs of SIADH [32].

Early signs and symptoms associated with mild to moderate hyponatremia are nausea, anorexia, thirst, weight gain, oliguria, weakness, fatigue, and muscle cramps, which usually becomes apparent when serum sodium falls to the $115-120 \mathrm{mEq}$ range. Neurology signs may include headache and mild altered mental status. Most of the patients in the study (41\%) were older people (more than 60 years). The average age was 60.69 years. 70,71 The study was different from the Appalachian et al. study, with an average age of 84 years [33]. These findings are consistent with other studies.

Overall sex distribution in the study showed male $(59 \%)$ preponderance, consistent with the study on Singapore, where male cases were $62 \%$. It is probably due to the fact that in developing countries like ours, females are underprivileged, both in the family and in society. Also, adolescent and adult females are reluctant to seek medical advice due to shyness and religious beliefs.

Previous work has suggested that the importance of the female gender as a risk factor for hyponatremia is confounded by low body weight. This fact is also reflected in the distribution of the hospital beds, the greater number of which, excluding those in the gynecological and obstetric units, are occupied by male patients. Ethnic differences in body composition, such as increased body fat in Asians compared to Caucasians, are documented and may also contribute.

This study found maximum (58\%) patient serum $\mathrm{Na}+$ was $>120 \mathrm{mmol} / \mathrm{l}$, followed by $38 \%$ serum $\mathrm{Na}+$ was $111-120 \mathrm{mmol} / \mathrm{L}$, and $4 \%$ serum $\mathrm{Na}+$ was $100-110$ mmol. The average serum $\mathrm{Na}+$ was 121.40 $\mathrm{mmol} / \mathrm{l}$. This finding consisted of the Casement et al. study. In previously published smaller studies, the mean serum $\mathrm{Na}+$ concentration was $124.8 \quad 5.9 \mathrm{mEq} / \mathrm{L}$. Mortality has ranged from 6.7 to $51 \%$ among hospitalized patients with sNa $<120 \mathrm{mEq} / \mathrm{L} \mathrm{[34].} \mathrm{The}$ reason for the marked variability in these single-center series is unknown, but we suspect it may reflect differences in case-mix in different populations.

This study showed total plasma osmolality was $260.40 \pm 8.51(\mathrm{mmol} / \mathrm{kg})$, urinary $\mathrm{Na}+$ was $134.65 \pm 55.81$ $\mathrm{mmol} / \mathrm{l}$, urinary osmolality was $408.05 \pm 157.02 \mathrm{mmol} / \mathrm{l}$, S. creatinine was $1.06 \pm 1.02 \mathrm{~m} / \mathrm{dl}$, and $\mathrm{S}$. uric acid was $3.35 \pm 0.75 \mathrm{mg} / \mathrm{dl}$. Al- Saimana [35] study laboratory tests show a serum sodium level of $110 \mathrm{mmol} / \mathrm{l}$; creatinine $3.6 \mathrm{mg} / \mathrm{dl}$; and plasma osmolality 278 $\mathrm{mmol} / \mathrm{kg}$ of water $(278 \mathrm{mOsm} / \mathrm{kg}$ of water). Other laboratory findings are a bicarbonate value of uric acid $0.42 \mathrm{mmol} / \mathrm{L} \quad(7.0 \mathrm{mg} / \mathrm{dl}) ;$ urine osmolality 450 $\mathrm{mmol} / \mathrm{kg}$ of water.

\section{CONCLUSION}

It's a common medical condition that can be caused by a variety of factors, including a deficiency of the antidiuretic hormone. Coma, fever, headache, weakness, disorientation, and convulsion were the most prevalent symptoms. Hemorrhagic stroke, followed by ischemic stroke, meningitis, encephalitis, pneumonia, and pulmonary $\mathrm{TB}$, were the most common causes of SIADH. Serum Na+ was low, plasma osmolality was low, creatinine was low, uric acid was low, and urine osmolality was greater. Hyponatremia should be regularly monitored in order to avoid this. Vaptan dosage should be reduced or fluids restricted as needed. Further improvement of the medical surveillance system, cessation of open selling of any medication other than over-the-counter drugs, increasing vigilance of the ignorant people through primary health care systems, and many more steps are required to be implemented. Seminars and workshops should be arranged in the different cities, Upazila or at union level with all related people and the policymakers who should gradually be convinced of the need to establish more specialized training centers in the country.

\section{LIMITATION}

It can be said that the data disclosed by the present study does not illuminate the complete situation of hyponatremia due to SIADH in our country. There were many limitations like unavailability of most of the medical facilities, lack of adequate sources, relatively 
short duration of the study (only 6 months) in a medical department of a medical college, and many others to come to a definite conclusion regarding the details of hyponatremia due to SIADH in the entire population. Therefore, further large-scale studies are needed to find out the total spectrum of etiology of SIADH and the real weight of the public health problem imposed by this disorder and formulate the total programs for management and prevention. While waiting for such long-term planning to devise and implement, we feel the immediate need of the facilities for the precise diagnosis and instituting a proper management program at least in all the academic hospitals.

\section{RECOMMENDATIONS}

This type of study should be done further with a large community-based sample size at a national level to find out the true picture of hyponatremia due to SIADH, which will help us early recognition and prompt precise management.

\section{REFERENCE}

1. Leaf, A., \& Mamby, A. R. (1952). An antidiuretic mechanism not regulated by extracellular fluid tonicity. The Journal of clinical investigation, 31(1), 60-71.

2. Schwartz, W. B. (1957). A syndrome of renal sodium loss and hyponatremia probably resulting from inappropriate secretion of antidiuretic hormone. Am J Med, 23, 529-542.

3. Rai, A., Whaley-Connell, A., McFarlane, S., \& Sowers, J. R. (2006). Hyponatremia, arginine vasopressin dysregulation, and vasopressin receptor antagonism. American journal of nephrology, 26(6), 579-589.

4. Decaux, G., Soupart, A., \& Vassart, G. (2008). Non-peptide arginine-vasopressin antagonists: the vaptans. The Lancet, 371(9624), 1624-1632.

5. Humes, H. D., Narins, R. G., \& Brenner, B. M. (1979). Disorders of water balance. Hospital practice, 14(3), 133-145.

6. Stelfox, H. T., Ahmed, S. B., Khandwala, F., Zygun, D., Shahpori, R., \& Laupland, K. (2008). The epidemiology of intensive care unit-acquired hyponatraemia and hypernatraemia in medicalsurgical intensive care units. Critical care, 12(6), $1-8$.

7. Hsu, Y. J., Chiu, J. S., Lu, K. C., Chau, T., \& Lin, S. H. (2005). Biochemical and etiological characteristics of acute hyponatremia in the emergency department. The Journal of emergency medicine, 29(4), 369-374.

8. Adrogué, H. J., \& Madias, N. E. (2000). Hyponatremia. New England Journal of Medicine, 342(21), 1581-1589.

9. Kravetz, J. D., \& Federman, D. G. (2002). Catassociated zoonoses. Archives of Internal Medicine, 162(17), 1945-1952.

10. Hoorn, E. J., Lindemans, J., \& Zietse, R. (2006). Development of severe hyponatraemia in hospitalized patients: treatment-related risk factors and inadequate management. Nephrology Dialysis Transplantation, 21(1), 70-76.

11. Stallard, T. C. (2017). Fluid, Electrolyte, \& AcidBase Emergencies. In: Stone, C. K., \& Humphries R. L., editors. CURRENT Diagnosis \& Treatment: Emergency Medicine [Internet]. 8th ed. New York, NY: McGraw-Hill Education. [cited 2021 Dec 23]. Available from: accessmedicine.mhmedical.com/content.aspx?aid= 1176295881

12. Arnqvist, H. J., Halban, P. A., Mathiesen, U. L., Zahnd, G., \& Von Schenck, H. (1993). Hypoglycaemia caused by atypical insulin antibodies in a patient with benign monoclonal gammopathy. Journal of internal medicine, 234(4), 421-427.

13. Decaux, G., \& Musch, W. (2008). Clinical laboratory evaluation of the syndrome of inappropriate secretion of antidiuretic hormone. Clinical Journal of the American Society of Nephrology, 3(4), 1175-1184.

14. Oh, J. Y., \& Shin, J. I. (2015). Syndrome of inappropriate antidiuretic hormone secretion and cerebral/renal salt wasting syndrome: similarities and differences. Frontiers in pediatrics, 2, 146.

15. Esposito, P., Piotti, G., Bianzina, S., Malul, Y., \& Dal Canton, A. (2011). The syndrome of inappropriate antidiuresis: pathophysiology, clinical management and new therapeutic options. Nephron Clinical Practice, 119(1), c62c73.

16. Langfeldt, L. A., \& Cooley, M. E. (2003). Syndrome of inappropriate antidiuretic hormone secretion in malignancy: review and implications for nursing management. Clinical journal of oncology nursing, 7(4), 425-430.

17. Artom, N., Oddo, S., Pende, A., Ottonello, L., Giusti, M., \& Dallegri, F. (2013). Syndrome of inappropriate antidiuretic hormone secretion and Ibuprofen, a rare association to be considered: Role of tolvaptan. Case reports in endocrinology, 2013, 818259.

18. Thomas, P. (2021). Syndrome of Inappropriate Antidiuretic Hormone Secretion (SIADH): Practice Essentials, Background, Pathophysiology. 2021 Oct 29 [cited 2021 Dec 23]; Available from: https://emedicine.medscape.com/article/246650overview

19. Smith, D., Moore, K., Tormey, W., Baylis, P. H., \& Thompson, C. J. (2004). Downward resetting of the osmotic threshold for thirst in patients with SIADH. American Journal of PhysiologyEndocrinology and Metabolism,287(5), E1019E1023.

20. Hannon, M. J., \& Thompson, C. J. (2010). The syndrome of inappropriate antidiuretic hormone: prevalence, causes and consequences. European journal of endocrinology, 162(Suppl1), S5-S12. 
21. Feldman, B. J., Rosenthal, S. M., Vargas, G. A., Fenwick, R. G., Huang, E. A., Matsuda-Abedini, M., ... \& Gitelman, S. E. (2005). Nephrogenic syndrome of inappropriate antidiuresis. New England Journal of Medicine, 352(18), 1884-1890.

22. Bartter, F. C., \& Schwartz, W. B. (1967). The syndrome of inappropriate secretion of antidiuretic hormone. The American journal of medicine, 42(5), 790-806.

23. Pillai, B. P., Unnikrishnan, A. G., \& Pavithran, P. V. (2011). Syndrome of inappropriate antidiuretic hormone secretion: Revisiting a classical endocrine disorder. Indian journal of endocrinology and metabolism, 15(Suppl3), S208.

24. Zietse, R., van der Lubbe, N., \& Hoorn, E. J. (2009). Current and future treatment options in SIADH. NDT plus, 2(suppl_3), iii12-iii19.

25. Schlanger, L. E., Bailey, J. L., \& Sands, J. M. (2010). Electrolytes in the aging. Advances in chronic kidney disease, 17(4), 308-319.

26. Kirpekar, V. C., \& Joshi, P. P. (2005). Syndrome of inappropriate $\mathrm{ADH}$ secretion (SIADH) associated with citalopram use. Indian journal of psychiatry, 47(2), 119-120.

27. Agha, A., Rogers, B., Mylotte, D., Taleb, F., Tormey, W., Phillips, J., \& Thompson, C. J. (2004). Neuroendocrine dysfunction in the acute phase of traumatic brain injury. Clinical endocrinology, 60(5), 584-591.

28. Hannon, M. J., Behan, L. A., O'Brien, M. M. C., Tormey, W., Ball, S. G., Javadpur, M., ... \& Thompson, C. J. (2014). Hyponatremia following mild/moderate subarachnoid hemorrhage is due to SIAD and glucocorticoid deficiency and not cerebral salt wasting. The Journal of Clinical Endocrinology \& Metabolism, 99(1), 291-298.
29. Le Berre, J. P., Desramé, J., Lecoules, S., Coutant, G., Béchade, D., \& Algayres, J. P. (2007). Hyponatrémie due au tramadol. La Revue de médecine interne, 28(12), 888-889.

30. Perry, A., Graffeo, C. S., Marcellino, C., Pollock, B. E., Wetjen, N. M., \& Meyer, F. B. (2018). Pediatric pituitary adenoma: case series, review of the literature, and a skull base treatment paradigm. Journal of Neurological Surgery Part B: Skull Base, 79(01), 91-114.

31. Ashraf, N., Locksley, R., \& Arieff, A. I. (1981). Thiazide-induced hyponatremia associated with death or neurologic damage in outpatients. The American journal of medicine, 70(6), 1163-1168.

32. Lieh-Lai, M. W., Stanitski, D. F., Sarnaik, A. P., Uy, H. G., Rossi, N. F., Simpson, P. M., \& Stanitski, C. L. (1999). Syndrome of inappropriate antidiuretic hormone secretion in children following spinal fusion. Critical care medicine, 27(3), 622-627.

33. Anpalahan, M. (2001). Chronic idiopathic hyponatremia in older people due to syndrome of inappropriate antidiuretic hormone secretion (SIADH) possibly related to aging. Journal of the American Geriatrics Society, 49(6), 788-792.

34. Chawla, A., Sterns, R. H., Nigwekar, S. U., \& Cappuccio, J. D. (2011). Mortality and serum sodium: do patients die from or with hyponatremia?. Clinical Journal of the American Society of Nephrology, 6(5), 960-965.

35. Al-Salman, J., Kemp, D., \& Randall, D. (2002). Evidence-based case reviews: hyponatremia. Western journal of medicine, 176(3), 173-176. 